\title{
Cerebrolysin effects on neurological outcomes and cerebral blood flow in acute ischemic stroke
}

This article was published in the following Dove Press journal:

Neuropsychiatric Disease and Treatment

3 December 2014

Number of times this article has been viewed

Mohammad Reza Amiri-

Nikpour ${ }^{1}$

Surena Nazarbaghi'

Babak Ahmadi-Salmasi'

Tayebeh Mokari²

Urya Tahamtan ${ }^{2}$

Yousef Rezaei ${ }^{3}$

'Department of Neurology, Imam Khomeini Hospital, ${ }^{2}$ School of Medicine, ${ }^{3}$ Seyyed-al-Shohada Heart Center, Urmia University of Medical Sciences, Urmia, Iran
Correspondence: Yousef Rezaei Seyyed-al-Shohada Heart Center, 17 Shahrivar Boulevard, Urmia 57I874944I, Iran

Tel +98912 $623 \quad 1864$

Fax +98 44I 2375907

Email yousefrezaei 1986@gmail.com
Background: Cerebrolysin, a brain-derived neuropeptide, has been shown to improve the neurological outcomes of stroke, but no study has demonstrated its effect on cerebral blood flow. This study aimed to determine the cerebrolysin impact on the neurological outcomes and cerebral blood flow.

Methods: In a randomized, double-blinded, placebo-controlled trial, 46 patients who had acute focal ischemic stroke were randomly assigned into two groups to receive intravenously either $30 \mathrm{~mL}$ of cerebrolysin diluted in normal saline daily for 10 days $(\mathrm{n}=23)$ or normal saline alone ( $\mathrm{n}=23$ ) adjunct to $100 \mathrm{mg}$ of aspirin daily. All patients were examined using the National Institutes of Health Stroke Scale and transcranial Doppler to measure the mean flow velocity and pulsatility index (PI) of their cerebral arteries at baseline as well as on days 30, 60, and 90 .

Results: The patients' mean age was $60 \pm 9.7$ years, and $51.2 \%$ of patients were male. The National Institutes of Health Stroke Scale was significantly lower in the cerebrolysin group compared with the placebo group on day 60 (median 10 , interquartile range $9-11, P=0.008$ ) and day 90 (median 11, interquartile range 10-13.5, $P=0.001$ ). The median of PI in the right middle cerebral artery was significantly lower in the cerebrolysin group compared with the placebo group on days 30,60 , and $90(P<0.05)$. One patient in the cerebrolysin group and two patients in the placebo group died before day 30 (4.3\% versus $8.7 \%)$.

Conclusion: Cerebrolysin can be useful to improve the neurological outcomes and the PI of middle cerebral artery in patients with acute focal ischemic stroke.

Keywords: ischemic stroke, cerebrolysin, neuroprotection, NIHSS, mean flow velocity, pulsatility index

\section{Introduction}

Cardiovascular diseases, including ischemic heart disease and stroke, are the main cause of mortality and morbidity worldwide. Based on the latest report on the global burden of diseases, their rankings have been dramatically increased from 1990 to 2010. ${ }^{1}$ Stroke results from a central nervous system focal injury attributable to cardiovascular origin causes. ${ }^{2,3}$ It is associated with some major complications, including post-stroke dementia, depression, fractures, and epilepsy. ${ }^{4}$ The management of stroke consists of primary prevention during an acute attack and secondary preventive strategies. ${ }^{4}$ Acute primary and secondary preventions as well as long-term secondary preventive strategies are the cornerstone of stroke management. The acute secondary preventions include antiplatelet agents, antihypertensives, statins, anticoagulants, and carotid endarterectomy; and the long-term secondary preventions are composed of antithrombotic agents, lipid modification, antihypertensive drugs, and multi-risk factor modification. ${ }^{4,5}$ The acute primary treatment is crucial to decrease the burden of stroke lesion, and therefore, some studies have focused on administering new therapies at presentation for improving the clinical outcomes of stroke. ${ }^{6}$ Cerebrolysin is one of 
the new agents used at the acute phase of stroke, which is a porcine brain-derived peptide consisting of low molecular weight neuropeptides and free aminoacids, ${ }^{7,8}$ and it acts as a neuroprotective and neurotrophic agent similar to growth and neurotrophic factors. ${ }^{9}$

Cerebrolysin safety and efficacy have been demonstrated in some neurological diseases, including acute ischemic stroke, ${ }^{7,10,11}$ brain traumatic injury, ${ }^{9,12,13}$ Alzheimer's disease,${ }^{14}$ Parkinson's disease, ${ }^{15}$ dementia, ${ }^{16,17}$ and autism or Asperger syndrome. ${ }^{18}$ This neuroprotective agent decreases the microglial cells' activity, and through implementing a neuroimmunotrophic effect leads to decrease in inflammation and neuronal cells' death in neurodegenerative diseases. ${ }^{19}$ Herein, in a randomized, double-blinded, placebo-controlled clinical trial, we sought to determine the effect of $30 \mathrm{~mL}$ of cerebrolysin diluted in normal saline daily for 10 days adjunct to $100 \mathrm{mg}$ of aspirin daily on the neurological outcomes as well as cerebral mean flow velocity and pulsatility index (PI) of cerebral arteries in patients who had been admitted to hospital with an acute focal ischemic stroke.

\section{Methods}

\section{Study cohort and protocol}

In a randomized, double-blinded, placebo-controlled clinical trial, patients who had signs and symptoms of acute brain stroke were assessed from March 2013 to March 2014. The baseline diagnosis of acute brain stroke was performed using the National Institutes of Health Stroke Scale (NIHSS), paraclinical examinations associated with imaging modalities. This study was approved by the local ethics committee of Urmia University of Medical Sciences, Urmia, West Azerbaijan Province, Iran. All participants also obtained consent forms before enrollment.

A total of 98 consecutive patients with suspected brain stroke were assessed for eligibility. Inclusion criteria included were as follows: i) both sexes with 18-85 years; ii) having focal neurological injury; iii) having ischemic stroke within 6-24 hours before admission; iv) having an acute focal ischemic stroke detected by computed tomography (CT) scan and/or magnetic resonance imaging (MRI); and v) NIHSS score of 6-22 at presentation. In addition, exclusion criteria consisted of rapid improvement of signs and symptoms and/ or complete resolving within 24 hours; having seizure upon the development of stroke; any conditions interfering with neurological examination such as severe dementia or psychological diseases; severe heart failure; acute myocardial infarction; pregnancy or breast-feeding; having significant systemic diseases associated with disability and decreased well-being; having systolic and diastolic blood pressure above $220 \mathrm{~mm} / \mathrm{Hg}$ and $120 \mathrm{~mm} / \mathrm{Hg}$, respectively; having a CT or an MRI suggesting acute or chronic hemorrhagic stroke and/or neoplasm; having hernia in the brain or increased intracranial pressure; having contraindication or sensitivity to take aspirin and/or cerebrolysin; taking other neuroprotective agents such as piracetam; and taking vasodilators such as nimodipine.

\section{Interventions and follow-up}

Out of a total of 98 patients assessed for eligibility, 46 patients entered into the study. All patients who met inclusion criteria were randomly assigned into two groups to receive intravenously either $30 \mathrm{~mL}$ of cerebrolysin diluted in normal saline once a day for 10 days $(n=23)$ or normal saline, as placebo, with a prescription order similar to the main drug $(n=23)$. In addition to the cerebrolysin and placebo, all of patients were given $100 \mathrm{mg}$ of aspirin daily. The enrolled patients underwent diagnostic interventions and received therapies within 6 hours after arriving to the hospital. During hospitalization, they also underwent rehabilitation therapy with the same protocols. After entering into two groups, at baseline, the patients' neurological conditions were examined using NIHSS, and transcranial Doppler (TCD) examination was also used to detect the mean flow velocity $(\mathrm{cm} / \mathrm{s})$ and PI in their right and left middle cerebral arteries as well as basilar artery. The mean flow velocities were detected between depths of $40 \mathrm{~mm}$ and $60 \mathrm{~mm}$ using a $2 \mathrm{MHz}$ probe from both temporal windows. The PI was defined as the difference between peak systolic and end-diastolic velocities divided by the mean flow velocity of the same artery. ${ }^{20}$ The NIHSS and TCD examinations were repeated on days 30,60, and 90 during the follow-up period. All patients whose NIHSS scores were $0-1$ or had a reduction in their NIHSS score more than 6 scores compared to their baseline NIHSS values were considered as responders.

\section{Primary and secondary endpoints}

Any changes in the NIHSS score during the 90-day follow-up were considered as primary endpoints. The enhancement in the mean flow velocity $(\mathrm{cm} / \mathrm{s})$ of cerebral arteries, including right and left middle cerebral arteries as well as basilar artery, and decrease in the PI of mentioned arteries were considered as secondary endpoints.

\section{Statistical analysis}

The normality of data distribution was assessed using Shapiro-Wilk test analysis. Categorical variables were 
analyzed using chi-square test, and continuous variables were analyzed by $t$-test or Mann-Whitney $U$-test as appropriate. The $P$-values less than 0.05 were considered statistically significant. All analyses were performed using SPSS software, version 18.0 (SPSS Inc, Chicago, IL, USA).

\section{Results}

\section{Characteristics}

Of 98 patients who were assessed for eligibility, 46 patients ( $46.9 \%$ recruitment rate) were assigned into the cerebrolysin $(n=23)$ and placebo $(n=23)$ groups. After receiving treatments, one patient in the cerebrolysin-received group and two patients in the placebo-received group died before day 30 (4.3\% versus $8.7 \%)$; they were excluded from the final analysis due to lack of measuring their outcomes at 90-day follow-up (Figure 1). The patients' mean age was $60 \pm 9.7$ years, and no significant difference was observed between the two groups $(P=0.987)$. Most patients were male $(51.2 \%)$, and there was no significant difference between the cerebrolysin and placebo groups $(P=0.650)$. Other demographics, including cerebrovascular risk factors and drug histories, are shown in Table 1. The anatomical part of stroke was predominantly located in anterior circulation of brain without significant difference $(69.8 \%, P=0.370)$.

\section{Neurological outcomes and cerebral blood flow evaluation}

The baseline NIHSS score was comparable between the groups (cerebrolysin median of 14, interquartile range 13-15 versus placebo median of 14 , interquartile range $12-16, P=0.432$ ); however, the NIHSS values were significantly lower in the cerebrolysin group compared with the placebo group on day 60 (median 10, interquartile range 9-11 versus median 12, interquartile range $10-14, P=0.008$ ) and day 90 (median 9 , interquartile range $8-10$ versus median 11 , interquartile range $10-13.5, P=0.001)$. The mean flow velocities in the right and left middle cerebral arteries and basilar artery were not significantly different except the velocity of right middle cerebral artery on day 30, which was higher in the placebo than that in the cerebrolysin group (cerebrolysin median of 45,

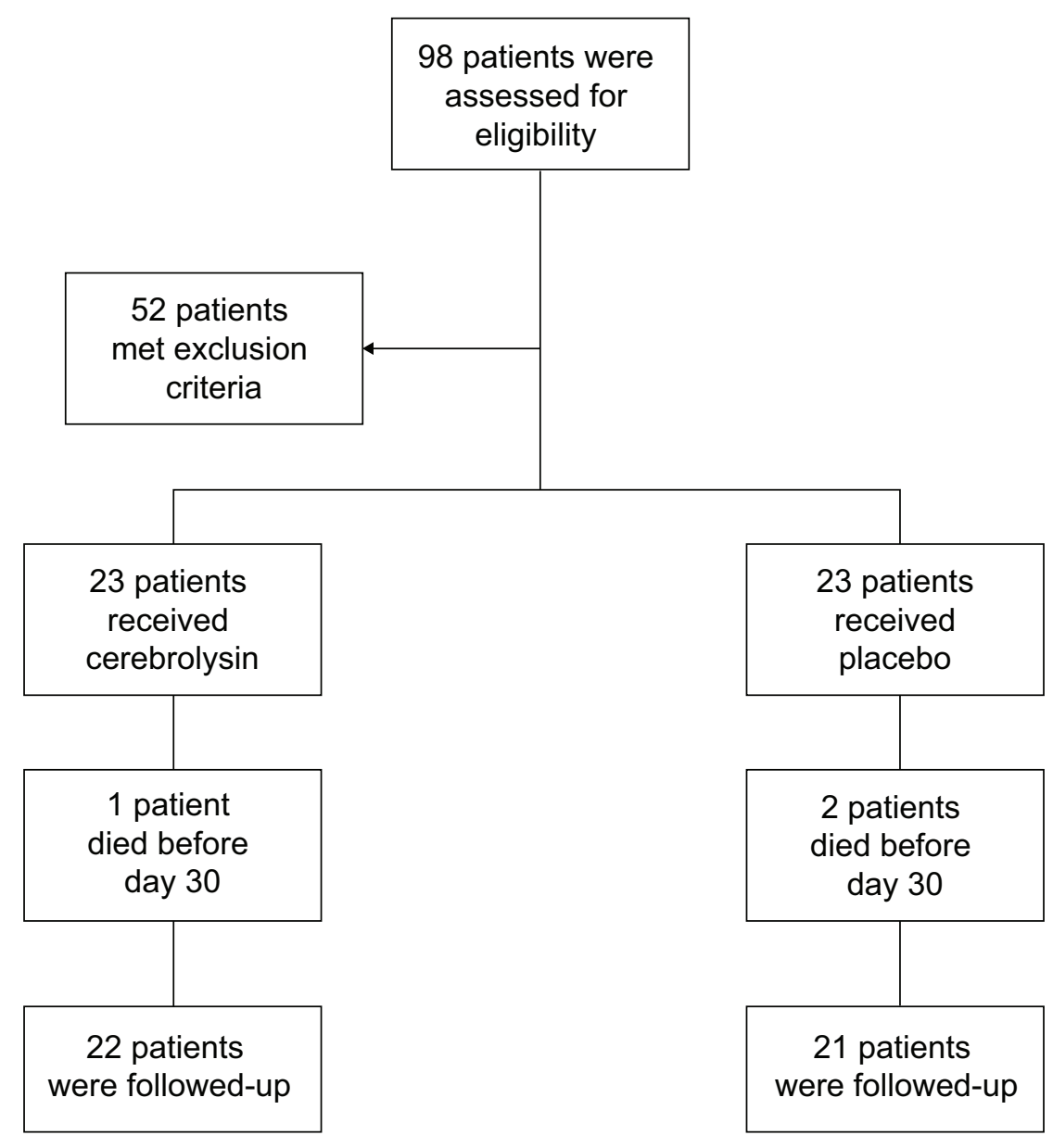

Figure I Study flow chart. 
Table I Baseline demographics and medical history of studied patients

\begin{tabular}{|c|c|c|c|c|}
\hline & Total $(n=43)$ & Cerebrolysin $(n=22)$ & Placebo $(n=2 I)$ & $P$-value \\
\hline Age (mean $\pm S D)$ & $60 \pm 9.7$ & $60 \pm 9.6$ & $60.1 \pm 10$ & 0.987 \\
\hline \multicolumn{5}{|l|}{ Sex, no (\%) } \\
\hline Male & $22(51.2 \%)$ & $12(54.5 \%)$ & $10(47.6 \%)$ & \multirow[t]{2}{*}{0.650} \\
\hline Female & $21(48.8 \%)$ & $10(45.5 \%)$ & II (52.4\%) & \\
\hline \multicolumn{5}{|l|}{ Risk factors, no (\%) } \\
\hline Ischemic heart disease & $7(16.3 \%)$ & $4(18.2 \%)$ & $3(14.3 \%)$ & I \\
\hline Diabetes mellitus & I8 (4I.9\%) & $8(36.4 \%)$ & $10(47.6 \%)$ & 0.455 \\
\hline Hypertension & $26(60.5 \%)$ & $13(59.1 \%)$ & $13(61.9 \%)$ & 0.850 \\
\hline Dyslipidemia & $23(53.5 \%)$ & II (50\%) & $12(57.1 \%)$ & 0.639 \\
\hline Smoking & $6(14 \%)$ & $3(13.6 \%)$ & $3(14.3 \%)$ & 1 \\
\hline \multicolumn{5}{|l|}{ Drug histories, no (\%) } \\
\hline$\beta$-blocker & $9(20.9 \%)$ & $4(18.2 \%)$ & $5(23.8 \%)$ & 0.721 \\
\hline ACE-I & $5(11.6 \%)$ & $3(13.6 \%)$ & $2(9.5 \%)$ & 1 \\
\hline Angiotensin receptor blocker & $13(30.2 \%)$ & $8(36.4 \%)$ & $5(23.8 \%)$ & 0.510 \\
\hline Calcium channel blocker & I (2.3\%) & $0(0 \%)$ & I (4.8\%) & 0.488 \\
\hline Diuretic & $9(20.9 \%)$ & $3(13.6 \%)$ & $6(28.6 \%)$ & 0.281 \\
\hline Statin & $24(55.8 \%)$ & $12(54.5 \%)$ & $12(57.1 \%)$ & 0.864 \\
\hline Antidiabetic & 18 (4I.9\%) & $8(36.4 \%)$ & $10(47.6 \%)$ & 0.455 \\
\hline Antidiabetic plus statin & $10(23.3 \%)$ & $3(13.6 \%)$ & $7(33.3 \%)$ & 0.162 \\
\hline Antidiabetic plus antihypertensive & $6(14 \%)$ & $4(18.2 \%)$ & $2(9.5 \%)$ & 0.664 \\
\hline Antihypertensive plus statin & 9 (20.9\%) & $4(18.2 \%)$ & $5(23.8 \%)$ & 0.721 \\
\hline \multicolumn{5}{|l|}{ Stroke location, no (\%) } \\
\hline Anterior circulation & $30(69.8 \%)$ & $14(63.6 \%)$ & $16(76.2 \%)$ & 0.370 \\
\hline Posterior circulation & $13(30.2 \%)$ & $8(36.4 \%)$ & $5(23.8 \%)$ & \\
\hline
\end{tabular}

Abbreviation: ACE-I, angiotensin-converting enzyme inhibitors.

interquartile range $38-52 \mathrm{~cm} / \mathrm{s}$ versus placebo median of 53 , interquartile range $49-57 \mathrm{~cm} / \mathrm{s}, P=0.033$ ). When comparing the PI values, the median of PI in the right middle cerebral artery was significantly lower in the cerebrolysin group compared with the placebo group on day $30(0.85$, interquartile range $0.8-1$ versus 1.1 , interquartile range $0.9-1.2, P=0.010$ ), day $60(0.9$, interquartile range $0.8-1$ versus 1.1 , interquartile range $1-1.2, P=0.001)$, and day $90(0.9$, interquartile range $0.8-1.1$ versus 1 , interquartile range $1-1.2, P=0.014$ ) (Table 2). In addition, we compared the outcomes between subgroups by age, $<65$ years and $\geq 65$ years, among those who received cerebrolysin (Table 3 ). None of the outcomes were associated with significant differences between the age groups except the flow velocity of basilar artery on day 60 , which was lower in the group of age $<65$ years than that of age $\geq 65$ years (median 28 , interquartile range $25-32$ versus median 34 , interquartile range $30-42, P=0.034$ ).

Responders were considered as patients whose NIHSS score was $0-1$ or decreased at least 6 scores or greater in comparison with baseline NIHSS score. Accordingly, three patients on day 60 and eight patients on day 90 in the cerebrolysin group had neurological improvement as a predefined responder. There was no responder in the placebo-received group during the 90-day follow-up period. The number of responders was significantly higher in the cerebrolysin-treated group compared with the placebo group on day 90 ( 8 versus $0, P=0.002$ ) (Figure 2 ).

\section{Discussion}

This study supports the previous studies in which it has been demonstrated that cerebrolysin administered intravenously can be useful to improve the neurological outcomes of patients with an acute focal ischemic stroke. We also found, for the first time, that the patients who received cerebrolysin had the decreased PI of right middle cerebral artery on days 30,60 , and 90 compared with those who received placebo. However, it was not effective in decreasing the mean flow velocity of middle cerebral and basilar arteries except the mean flow velocity of right middle cerebral artery on day 60 . On the other hand, the mean flow velocity of basilar artery was significantly lower in the patients $<65$ years of age compared with that in patients $>65$ years of age who received cerebrolysin.

Neurotrophic molecules have important role in microglial cells' activity; therefore, agents with neurotrophic properties will be the new strategies for treatment and prevention in neurodegenerative diseases. ${ }^{19}$ Cerebrolysin is the only drug containing neurotrophic molecules, which has been provided from some brain-derived proteins. Several mechanisms have been postulated for cerebrolysin activity, 
Table 2 Clinical outcomes and cerebral blood flow indices measured during 90-day follow-up

\begin{tabular}{|c|c|c|c|c|}
\hline & Total $(n=43)$ & Cerebrolysin $(n=22)$ & Placebo $(n=2 I)$ & $P$-value \\
\hline \multicolumn{5}{|c|}{ NIHSS score } \\
\hline Baseline & $14(13,16)$ & $14(13,15)$ & $14(12,16)$ & 0.432 \\
\hline Day 30 & $12(10,13)$ & II $(10,12)$ & $12(10,14)$ & 0.092 \\
\hline Day 60 & $10.5(9,12)$ & $10(9,11)$ & $12(10,14)$ & 0.008 \\
\hline Day 90 & $10(8,11)$ & $9(8,10)$ & II (I0, I3.5) & 0.001 \\
\hline \multicolumn{5}{|c|}{ Velocity of right $\mathrm{MCA}, \mathrm{cm} / \mathrm{s}$} \\
\hline Baseline & $48(40,57)$ & $47(39,50)$ & $48(4 I, 64)$ & 0.343 \\
\hline Day 30 & $49(43,56)$ & $45(38,52)$ & $53(49,57)$ & 0.033 \\
\hline Day 60 & $50(44,55)$ & $46(42,52)$ & $5 \mathrm{I}(49,57)$ & 0.055 \\
\hline Day 90 & $50(44,55)$ & $48(4 I, 53)$ & $54.5(49,56.5)$ & 0.065 \\
\hline \multicolumn{5}{|c|}{ Velocity of left MCA, $\mathrm{cm} / \mathrm{s}$} \\
\hline Baseline & $47(40,56)$ & $49(38,56)$ & $45(40,50)$ & 0.806 \\
\hline Day 30 & $47(42,55)$ & $46(40,51)$ & $47(43,59)$ & 0.768 \\
\hline Day 60 & $48.5(41,57)$ & $47(4 I, 52)$ & $50(45,58)$ & 0.789 \\
\hline Day 90 & $50(43,55)$ & $49(43,52)$ & $50(48,55)$ & 0.638 \\
\hline \multicolumn{5}{|c|}{ Velocity of basilar artery, $\mathrm{cm} / \mathrm{s}$} \\
\hline Baseline & $30(21,42)$ & $31.5(25,37)$ & $28(18,47)$ & 0.504 \\
\hline Day 30 & $30(20,42)$ & $31(25,38)$ & $28(20,48)$ & 0.610 \\
\hline Day 60 & $30(25,40)$ & $30(27,36)$ & $30(20,49)$ & $0.34 I$ \\
\hline Day 90 & $33(28,43)$ & $32(29,38)$ & $36.5(27,46)$ & 0.657 \\
\hline \multicolumn{5}{|c|}{ Right MCA PI } \\
\hline Baseline & $0.9(0.8,1.1)$ & $0.85(0.7, \mathrm{I} . \mathrm{I})$ & I $(0.8, \mid$ I.2) & 0.364 \\
\hline Day 30 & $\mathrm{I}(0.8, \mathrm{I} . \mathrm{I})$ & $0.85(0.8,1)$ & I.I $(0.9,1.2)$ & 0.010 \\
\hline Day 60 & I $(0.8, I . I)$ & $0.9(0.8, I)$ & I.I (I, I.2) & 0.001 \\
\hline Day 90 & I $(0.9, I . I)$ & $0.9(0.8,1.1)$ & I $(I, I .2)$ & 0.014 \\
\hline \multicolumn{5}{|l|}{ Left MCA PI } \\
\hline Baseline & $\mathrm{I}(0.8, \mid \mathrm{I})$ & $\mathrm{I}(0.8, \mathrm{I} . \mathrm{I})$ & I.I $(0.8,1.3)$ & 0.345 \\
\hline Day 30 & $\mathrm{I}(0.8, \mathrm{I} . \mathrm{I})$ & $\mathrm{I}(0.8, \mathrm{I} . \mathrm{I})$ & I.I $(0.9,1.2)$ & 0.286 \\
\hline Day 60 & I $(0.9,1 . I)$ & I $(0.9,1 . I)$ & I $(0.9,1.1)$ & 0.627 \\
\hline Day 90 & I $(0.9, \mid .2)$ & I $(0.8, I . I)$ & I $(0.9, \mid .2)$ & 0.277 \\
\hline \multicolumn{5}{|c|}{ Basilar artery PI } \\
\hline Baseline & $\mathrm{I}(0.8, \mathrm{I} . \mathrm{I})$ & I $(0.9,||)$. & $0.9(0.8,1.1)$ & 0.576 \\
\hline Day 30 & I $(0.8,|$.$| )$ & I $(0.8, I . I)$ & $0.9(0.8,1)$ & 0.384 \\
\hline Day 60 & $0.95(0.9,1.1)$ & $0.9(0.9,1.1)$ & I $(0.9,1.1)$ & 0.931 \\
\hline Day 90 & $\mathrm{I}(0.8, \mathrm{I} . \mathrm{I})$ & $\mathrm{I}(0.9, \mathrm{I} . \mathrm{I})$ & $0.95(0.8, I . I)$ & 0.828 \\
\hline
\end{tabular}

Abbreviations: MCA, middle cerebral artery; NIHSS, National Institutes of Health Stroke Scale; PI, pulsatility index.

which can act through the inhibition of apoptosis and the production of free radicals and lipid preoxidation. ${ }^{21}$ All these pathways contribute to the inhibition of neuronal death and inflammation in the settings of neurodegenerative diseases. ${ }^{19,21}$

Cerebrolysin has long been used for treating ischemic stroke in the animal model and human studies. In an animal model of focal ischemic stroke, it has been shown that the cerebrolysin administered intravenously was effective in reducing the neurological deficits, ${ }^{22}$ and according to another one, the effect of $2.5 \mathrm{~mL} / \mathrm{kg}$ of cerebrolysin on the improvement of neurological outcomes was demonstrated, in which sensorimotor functions were improved; however, no impact on infarct volume was found. ${ }^{23}$ In addition to these animal models, the effect of cerebrolysin on acute focal ischemic stroke in clinical studies has been found to be promising. A study of ischemic stroke patients has reported that $50 \mathrm{~mL}$ of cerebrolysin for 7 days compared with placebo resulted in the improvement of outcomes at 90 -day follow-up. ${ }^{10}$ Furthermore, the combination of cerebrolysin and thrombolytic therapy was assessed in acute ischemic stroke, in which no significant difference was observed regarding the improvement of neurological outcomes at day 90 , although the responders defined that the NIHSS score $0-1$ or reduction in NIHSS score of more than 6 scores was significantly higher in the patients who received cerebrolysin adjunct to thrombolytic therapy compared with those who received thrombolytic plus placebo. ${ }^{24}$ In contrast, a large-scale trial has failed to show the effect of cerebrolysin on neurological outcomes, although they found that there was a trend toward patients with severe ischemic stroke (NIHSS $>12$ ) to have better outcomes and less mortality compared with the placebo group. ${ }^{7}$ In the present study, we found that administering $30 \mathrm{~mL}$ of cerebrolysin infused daily for 10 days associated with $100 \mathrm{mg}$ of aspirin daily led to the 
Table 3 Comparison of outcomes measured during 90-day follow-up between the age subgroups among cerebrolysin-treated patients

\begin{tabular}{|c|c|c|c|}
\hline & Age $<65(n=13)$ & Age $\geq 65(n=9)$ & $P$-value \\
\hline \multicolumn{4}{|c|}{ NIHSS score } \\
\hline Baseline & $14(14,16)$ & $14(13,15)$ & 0.324 \\
\hline Day 30 & $11(10,12)$ & $11(10,12)$ & 0.794 \\
\hline Day 60 & $10(9,11)$ & $9(9,10)$ & 0.702 \\
\hline Day 90 & $9(8,10.5)$ & $9(8,10)$ & 0.651 \\
\hline \multicolumn{4}{|c|}{ Velocity of right $\mathrm{MCA}, \mathrm{cm} / \mathrm{s}$} \\
\hline Baseline & $44(40,49)$ & $48(39,51)$ & 0.845 \\
\hline Day 30 & $44(39,49)$ & $48(37,52)$ & 0.695 \\
\hline Day 60 & $44(4 I, 50)$ & $49(42,54)$ & 0.508 \\
\hline Day 90 & $46(40,49.5)$ & $50(42,55)$ & 0.345 \\
\hline \multicolumn{4}{|c|}{ Velocity of left MCA, $\mathrm{cm} / \mathrm{s}$} \\
\hline Baseline & $45(40,50)$ & $44(42,59)$ & 0.744 \\
\hline Day 30 & $42(40,49)$ & $48(45,59)$ & 0.126 \\
\hline Day 60 & $42.5(39,5 I)$ & $50(47,60)$ & 0.129 \\
\hline Day 90 & $44.5(41.5,50.5)$ & $51(49,62)$ & 0.095 \\
\hline \multicolumn{4}{|c|}{ Velocity of basilar artery, $\mathrm{cm} / \mathrm{s}$} \\
\hline Baseline & $28(2 \mathrm{I}, 34)$ & $34(27,42)$ & 0.262 \\
\hline Day 30 & $28(2 I, 37)$ & $34(26,42)$ & 0.324 \\
\hline Day 60 & $28(25,32)$ & $34(30,42)$ & 0.034 \\
\hline Day 90 & $30.5(28,35.5)$ & $34(31,43)$ & 0.219 \\
\hline \multicolumn{4}{|c|}{ Right MCA PI } \\
\hline Baseline & I $(0.7, I)$ & $0.8(0.8, I .1)$ & 0.744 \\
\hline Day 30 & $\mathrm{I}(0.7, \mathrm{I})$ & $0.8(0.8, I)$ & 0.948 \\
\hline Day 60 & $0.85(0.8,1.05)$ & $0.9(0.8, I)$ & 0.917 \\
\hline Day 90 & $0.9(0.8,1.1)$ & $0.9(0.8, I . I)$ & 0.972 \\
\hline \multicolumn{4}{|c|}{ Left MCA PI } \\
\hline Baseline & I $(0.8, I . I)$ & I $(0.8,1.09)$ & 0.647 \\
\hline Day 30 & $0.9(0.8,1.1)$ & I $(0.9,1.09)$ & 0.431 \\
\hline Day 60 & $0.95(0.8,1.05)$ & I $(0.9,1.17)$ & 0.422 \\
\hline Day 90 & I $(0.8,1.05)$ & $0.9(0.8,1.25)$ & 0.702 \\
\hline \multicolumn{4}{|c|}{ Basilar artery PI } \\
\hline Baseline & I $(0.9, I . I)$ & $0.9(0.8, I .1)$ & 0.647 \\
\hline Day 30 & I (I, I.I) & $0.8(0.8, I)$ & 0.357 \\
\hline Day 60 & $0.95(0.9,1.05)$ & $0.9(0.8,1.1)$ & 0.651 \\
\hline Day 90 & $0.95(0.9,1.05)$ & $\mathrm{I}(0.8, \mathrm{I} . \mathrm{I})$ & 0.862 \\
\hline
\end{tabular}

Abbreviations: MCA, middle cerebral artery; NIHSS, National Institutes of Health Stroke Scale; PI, pulsatility index.

significant improvement of neurological functions compared with placebo at 90-day follow-up; moreover, for the first time, this regimen resulted in decrease in the PI of the right middle cerebral artery. We think that given these findings in

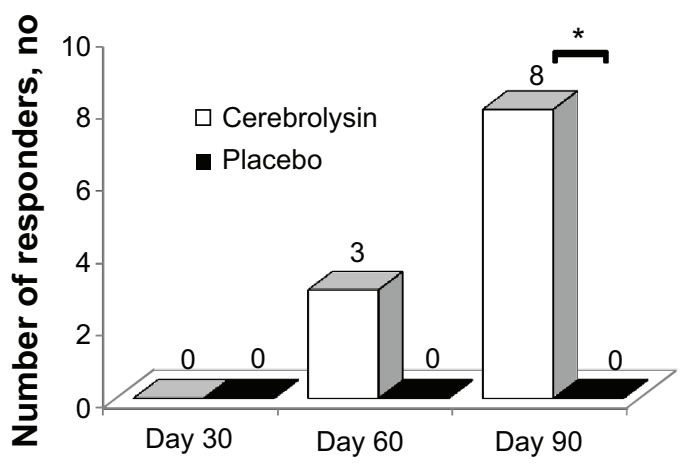

Figure 2 Comparison of responders between study groups during 90-day follow-up. Note: *A significant difference between both groups was observed, $P=0.002$. terms of cerebrolysin effects on animal and human models of acute focal ischemic stroke, further large-scale clinical trial studies are required to clarify more these notions so that this agent can be implemented in an acute setting for improving patients' outcome.

Neuroprotective agents do not have a defined golden time of administering; therefore, those can be used for more proportion of stroke patients. ${ }^{25}$ In a study of focal ischemic stroke in rats, it has been found that cerebrolysin administered 24 hours or 48 hours after stroke onset resulted in greater sensorimotor improvement and decrease in infarct volume as compared to administering at 72 hours post-stroke. ${ }^{23}$ In another study, cerebrolysin has been shown to have a wide therapeutic time window, which can be used to reduce neuronal damage even after 72 hours post-stroke. ${ }^{26} \mathrm{We}$ prescribed the cerebrolysin within 6 hours after arriving to 
the hospital in the patients whose stroke had been started 6-24 hours before admission, and thus, we can state that the therapeutic time window of this study was exactly less than 48 hours. Besides these findings, a clinical study focusing on the treatment time onset will be of great importance to clarify this substantial point of clinical practice.

According to an experimental study of cerebrolysin effect on focal cerebral ischemia, administering $2.5 \mathrm{~mL} / \mathrm{kg}$ of cerebrolysin resulted in reducing infarct volume, morbidity, and mortality; however, the doses of $1 \mathrm{~mL} / \mathrm{kg}$ and $5 \mathrm{~mL} / \mathrm{kg}$ were ineffective. $^{22}$ In contrast, in a rat model of middle cerebral artery occlusion, cerebrolysin at a dose of $2.5 \mathrm{~mL} / \mathrm{kg}$ did not significantly reduce infarct volume as compared to a dose of $5 \mathrm{~mL} / \mathrm{kg} .{ }^{27}$ In addition, it has been reported that multiple doses might have great benefit to save neurons in ischemic brain tissue. ${ }^{26}$ In a stroke population, administering $50 \mathrm{~mL}$ of cerebrolysin was more effective than $10 \mathrm{~mL}$ for reducing the infarct volume and extension of ischemia. ${ }^{28}$ Because there are no clinical trials in terms of comparing different doses of cerebrolysin, we cannot definitely conclude whether the efficacy of this agent is dose dependent or not. Dose-finding studies are required to find the best dose of cerebrolysin.

As it has been proposed, cerebral autoregulatory mechanism contributes to the maintenance of sufficient mean flow velocity and decrease in the peripheral resistance in cerebral arteries to perfuse the ipsilateral hemisphere after the development of stroke. ${ }^{20}$ The TCD ultrasound examination is a tool for determining the mean flow velocity and PI of cerebral arteries. An increased mean flow velocity of cerebral artery measured by TCD examination could be interpreted as an indirect indicative of increasing cerebral perfusion. ${ }^{29}$ Moreover, the enhancement of PI of cerebral artery has been found to be associated with arterial resistance, and increased values correlated with the calcification of intracranial artery. ${ }^{30} \mathrm{In}$ our study, all mean flow velocities measured in the cerebral arteries did not significantly change during follow-up, which may be interpreted as the absence of cerebrolysin efficacy in increasing cerebral blood flow, although it was effective to reduce the flow velocity of the right middle cerebral artery on day 30 , and also the mean flow velocity of basilar artery in patients younger than 65 years was lower than older ones who received cerebrolysin. However, the PI of the right middle cerebral artery was significantly lower on days 30 , 60 , and 90 in the cerebrolysin-treated patients compared with patients who received placebo, which indicated lower arterial resistance in the treatment group compared with placebo group. We think that this paradoxical finding might be attributed to the effect of small sample size or difference in the extension of arterial calcification/stenosis, which might influence the cerebrolysin impact on cerebral blood flow. This study is the first one showing the effect of cerebrolysin on the PI of cerebral artery, and further studies are needed to explore this relationship.

One of the main factors affecting on the functional outcomes and mortality of stroke is the patients' age, which is being considered as a nonmodifiable risk factor for stroke. Aged people have shown to have worse prognosis in comparison with young or late middle age ones. ${ }^{31}$ In the present study, we compared the outcomes measured at 90-day follow-up period between the groups by age, $<65$ years and $\geq 65$ years, among patients who received cerebrolysin, which were not associated with significant improvements except the flow velocity of the basilar artery, which was lower in the patients younger than 65 years than that of ones older than 65 years. However, according to these findings and the lack of evidence in terms of the age-related response to cerebrolysin, we cannot definitely conclude whether cerebrolysin effects are age related or not.

The present study has some limitations based on its design and inevitable shortcomings. First, the small sample size is a major limitation, which might contribute to inability in showing age-related response to treatment. Indeed, we did not measure the grade of arterial stenosis and the volume of infarct lesion, which might also be associated with different functional recovery and prognosis in the patients. Further large-scale studies focusing on these limitations are required to clarify these important issues.

\section{Conclusion}

The administration of $30 \mathrm{~mL}$ of cerebrolysin diluted in normal saline once a day for 10 days adjunct to $100 \mathrm{mg}$ of aspirin daily can be useful for improving the neurological outcomes of patients who had acute focal ischemic stroke. Moreover, it was associated with a decrease in the PI of the right middle cerebral artery on days 30, 60, and 90 .

\section{Acknowledgments}

We thank to the vice-chancellor of research in Urmia University of Medical Sciences for providing the grant of this study. Moreover, we would like to greatly thank all members of emergency department of Imam Khomeini Hospital, Urmia, West Azerbaijan Province, Iran, for helping us in collecting the study data.

\section{Disclosure}

All authors declare that there are no conflicts of interest. 


\section{References}

1. Murray CJ, Lopez AD. Measuring the global burden of disease. NEngl J Med. 2013;369(5):448-457.

2. Sacco RL, Kasner SE, Broderick JP, et al; American Heart Association Stroke Council, Council on Cardiovascular Surgery and Anesthesia, Council on Cardiovascular Radiology and Intervention, Council on Cardiovascular and Stroke Nursing, Council on Epidemiology and Prevention, Council on Peripheral Vascular Disease, Council on Nutrition, Physical Activity and Metabolism. An updated definition of stroke for the 21st century: a statement for healthcare professionals from the American Heart Association/American Stroke Association. Stroke. 2013;44(7):2064-2089.

3. Amiri-Nikpour MR, Nazarbaghi S, Hamdi-Holasou M, Rezaei Y. An open-label evaluator-blinded clinical study of minocycline neuroprotection in ischemic stroke: gender-dependent effect. Acta Neurol Scand. 2014.

4. Rothwell PM, Algra A, Amarenco P. Medical treatment in acute and long-term secondary prevention after transient ischaemic attack and ischaemic stroke. Lancet. 2011;377(9778):1681-1692.

5. Donnan GA, Fisher M, Macleod M, Davis SM. Stroke. Lancet. 2008; 371(9624):1612-1623.

6. Albers GW, Goldstein LB, Hess DC, et al; STAIR VII Consortium. Stroke Treatment Academic Industry Roundtable (STAIR) recommendations for maximizing the use of intravenous thrombolytics and expanding treatment options with intra-arterial and neuroprotective therapies. Stroke. 2011;42(9):2645-2650.

7. Heiss WD, Brainin M, Bornstein NM, Tuomilehto J, Hong Z. Cerebrolysin in patients with acute ischemic stroke in Asia: results of a double-blind, placebo-controlled randomized trial. Stroke. 2012;43(3):630-636.

8. Tatebayashi Y, Lee MH, Li L, Iqbal K, Grundke-Iqbal I. The dentate gyrus neurogenesis: a therapeutic target for Alzheimer's disease. Acta Neuropathol. 2003;105(3):225-232.

9. Zhang Y, Chopp M, Meng Y, et al. Improvement in functional recovery with administration of Cerebrolysin after experimental closed head injury. J Neurosurg. 2013;118(6):1343-1355.

10. Aminianfar M, Salehi H, Saidi A, Ranjbar Naeeni A, Rastgo F. The Cerebrolysin efficacy in acute ischemic stroke. Ann Mil Health Sci Res. 2013;10(4):293-299.

11. Ladurner G, Kalvach P, Moessler H. Neuroprotective treatment with cerebrolysin in patients with acute stroke: a randomised controlled trial. J Neural Transm. 2005;112(3):415-428.

12. Chen CC, Wei ST, Tsaia SC, Chen XX, Cho DY. Cerebrolysin enhances cognitive recovery of mild traumatic brain injury patients: double-blind, placebo-controlled, randomized study. $\mathrm{Br} J$ Neurosurg. 2013;27(6):803-807.

13. Wong GK, Zhu XL, Poon WS. Beneficial effect of cerebrolysin on moderate and severe head injury patients: result of a cohort study. Acta Neurochir Suppl. 2005;95:59-60.

14. Alvarez XA, Cacabelos R, Sampedro C, et al. Efficacy and safety of Cerebrolysin in moderate to moderately severe Alzheimer's disease: results of a randomized, double-blind, controlled trial investigating three dosages of Cerebrolysin. Eur J Neurol. 2011;18(1):59-68.

15. Lukhanina EP, Karaban IN, Burenok Iu A, Mel'nik NA, Berezetskaia NM. [Effect of cerebrolysin on the electroencephalographic indices of brain activity in Parkinson's disease]. Zh Nevrol Psikhiatr Im S S Korsakova. 2004;104(7):54-60. Russian.
16. Chen N, Yang M, Guo J, Zhou M, Zhu C, He L. Cerebrolysin for vascular dementia. Cochrane Database Syst Rev. 2013;1:CD008900.

17. Plosker GL, Gauthier S. Cerebrolysin: a review of its use in dementia. Drugs Aging. 2009;26(11):893-915.

18. Krasnoperova MG, Bashina VM, Skvortsov IA, Simashkova NV. [The effect of cerebrolysin on cognitive functions in childhood autism and in Asperger syndrome]. Zh Nevrol Psikhiatr Im S S Korsakova. 2003; 103(6): 15-18.

19. Alvarez XA, Lombardi VR, Fernández-Novoa L, et al. Cerebrolysin reduces microglial activation in vivo and in vitro: a potential mechanism of neuroprotection. J Neural Transm Suppl. 2000;59:281-292.

20. Heyer EJ, Mergeche JL, Connolly ES Jr. Middle cerebral artery pulsatility index and cognitive improvement after carotid endarterectomy for symptomatic stenosis. J Neurosurg. 2014;120(1):126-131.

21. Formichi P, Radi E, Battisti C, Di Maio G, Muresanu D, Federico A. Cerebrolysin administration reduces oxidative stress-induced apoptosis in lymphocytes from healthy individuals. J Cell Mol Med. 2012;16(11): 2840-2843.

22. Hanson LR, Liu XF, Ross TM, et al. Cerebrolysin reduces infarct volume in a rat model of focal cerebral ischemic damage. Am J Neuroprotec Neuroregen. 2009;1(1):60-66.

23. Ren J, Sietsma D, Qiu S, Moessler H, Finklestein SP. Cerebrolysin enhances functional recovery following focal cerebral infarction in rats. Restor Neurol Neurosci. 2007;25(1):25-31.

24. Lang W, Stadler CH, Poljakovic Z, Fleet D. A prospective, randomized, placebo-controlled, double-blind trial about safety and efficacy of combined treatment with alteplase (rt-PA) and Cerebrolysin in acute ischaemic hemispheric stroke. Int J Stroke. 2013;8(2):95-104.

25. Davis S, Lees K, Donnan G. Treating the acute stroke patient as an emergency: current practices and future opportunities. Int J Clin Pract. 2006;60(4):399-407.

26. Schauer E, Wronski R, Patockova J, et al. Neuroprotection of cerebrolysin in tissue culture models of brain ischemia: post lesion application indicates a wide therapeutic window. J Neural Transm. 2006; 113(7):855-868.

27. Zhang C, Chopp M, Cui Y, et al. Cerebrolysin enhances neurogenesis in the ischemic brain and improves functional outcome after stroke. J Neurosci Res. 2010;88(15):3275-3281.

28. Skvortsova VI, Stakhovskaia LV, Gubskii LV, Shamalov NA, Tikhonova IV, Smychkov AS. [A randomized, double-blind, placebocontrolled study of Cerebrolysin safety and efficacy in the treatment of acute ischemic stroke]. Zh Nevrol Psikhiatr Im S S Korsakova. 2004; (suppl 11):51-55.

29. Bavarsad Shahripour R, Shamsaei G, Pakdaman H, et al. The effect of NeuroAiD (MLC601) on cerebral blood flow velocity in subjects' post brain infarct in the middle cerebral artery territory. Eur J Intern Med. 2011;22(5):509-513.

30. Park KY, Chung PW, Kim YB, Moon HS, Suh BC, Yoon WT. Increased pulsatility index is associated with intracranial arterial calcification. Eur Neurol. 2013;69(2):83-88.

31. Buga AM, Di Napoli M, Popa-Wagner A. Preclinical models of stroke in aged animals with or without comorbidities: role of neuroinflammation. Biogerontology. 2013;14(6):651-662.
Neuropsychiatric Disease and Treatment

\section{Publish your work in this journal}

Neuropsychiatric Disease and Treatment is an international, peerreviewed journal of clinical therapeutics and pharmacology focusing on concise rapid reporting of clinical or pre-clinical studies on a range of neuropsychiatric and neurological disorders. This journal is indexed on PubMed Central, the 'PsycINFO' database and CAS,
Dovepress

and is the official journal of The International Neuropsychiatric Association (INA). The manuscript management system is completely online and includes a very quick and fair peer-review system, which is all easy to use. Visit http://www.dovepress.com/testimonials.php to read real quotes from published authors. 